\title{
AISI D2 Soğuk İş Takım Çeliğinin Elektro Erozyon Tekniği İle İşlenebilirliğinin Deneysel Olarak İncelenmesi
}

\author{
Ali KALYON ${ }^{1 *}$ \\ ${ }^{1}$ Asst. Prof., Karabük University, Deparmant of Manufacturing Engineering, Orcid id: 0000-0003-3300-1336
}

Geliş Tarihi/Received: 09.12.2018

Kabul Tarihi/Accepted: 22.02.2019
Doi: dx.doi.org/10.31200/makuubd.494265

Araştırma Makalesi/Research Article

\section{ÖZET}

$\mathrm{Bu}$ çalışmada elektro erozyon ile işlemede (EEI) iş parçası ve elektrot çifti için işleme parametrelerinin etkileri deneysel olarak incelenmiştir. Deneysel çalışmada elektrot olarak bakır, iş parçası malzemesi olarak AISI D2 soğuk iş takım çeliği kullanılmıştır. İşleme parametreleri olarak boşalım akımı ve vurum süresi için sırasıyla üç farklı seviye belirlemiştir. Deneysel çalışma sonucunda iş parçası yüzey pürüzlülükleri ölçülmüştür. İş parçası işleme hızı, elektrot aşınma hızı ve bağıl aşınma değerleri hesaplanmıştır. Elde edilen ölçüm ve hesaplama sonuçları grafikler, SEM ve mikroskop görüntüleri kullanılarak yorumlanmıştır. Deneysel çalışma sonucunda boşalım akımının ve vurum süresinin artmasının yüzey pürüzlülüğü ve elektrot aşınma hızını olumsuz, iş parçası işleme hızını olumlu etkilediği belirlenmiştir.

Anahtar kelimeler: Elektro Erozyon ile İşleme, AISI D2, Bakır.

\section{Experimental Investigation of the Machinability of AISI D2 Cold Work Tool Steel With Electro Discharge Technique}

\begin{abstract}
In this work, the effects of machining parameters for workpiece and electrode pair in electro discharge machining (EDM) have been experimentally investigated. In the experimental work, copper was used as the electrode, and AISI D2 cold work tool steel was used as the workpiece material. The processing parameters specify three different levels for the discharge current and the pulse duration, respectively. After experiments carried out surface roughness was measured. Material removal rate, tool wear rate and relative wear were calculated.

* Sorumlu yazar/Corresponding author

E-mail/e-ileti: alikalyon@karabuk.edu.tr
\end{abstract}


Obtained measurement and calculation results are interpreted using graphs, SEM and microscope images. As a result of the experimental study, it has been determined that the increase of the discharge current and the pulse duration affects the surface roughness and the electrode wear rate negatively and affect the material removal rate positively.

Keywords: EDM, AISI D2, Copper.

\section{GÍRİŞ}

Elektro erozyon ile işleme (EEI), karmaşık şekillerin ve küçük deliklerin yüksek doğrulukta üretilmesi için en başarılı ve yaygın kabul gören geleneksel olmayan bir imalat işlemidir (Jamwal vd., 2018:433). Konvansiyonel işleme işlemi ile imal edilen sert ve kırılgan malzemeler aşırı takım aşınması ve masrafa neden olmaktadır. EEİ tekniği kalıpçılık alanında özellikle keskin köşelere sahip formların oluşturulmasında kullanılmaktadır. Ayrıca işleme esnasında kesme kuvvetinin oluşmaması ve sert parçaların kolaylıkla işlenebilmesi EEİ imalat yönteminin tercih edilmesini sağlamaktadır. İşleme hızının yavaş olması EEİ tekniğinin zayıf yönüdür. İş parçası ve elektrot arasında doğrudan bir temas olmadığından EEİ yönteminde iş parçası üzerinde mekanik bir baskı yoktur. EEİ'de elektrot olarak elektrik iletkenliğine sahip tüm malzemeler kullanılabilir. Bakır, pirinç, alüminyum ve grafit sıklıkla elektrot olarak kullanılan malzemelerdir (Anjum vd., 2017:1765; Kumar vd., 2017:223; Kumari vd., 2018:2079).

Elektriksel kıvılcımla aşındırma yöntemi olarak adlandırılan elektro erozyon ile işleme (EEI) elektriksel iletkenliğe sahip bir iş parçasından yüksek frekansa sahip elektrik boşalımlarının uygulanması ile iş parçasından küçük partiküllerin ergitilerek veya buharlaşma yöntemi ile yüzeyden koparılması prensibine dayanan alışılmamış imalat yöntemidir. Şekil 1 'de EEİ şematik olarak gösterilmektedir.

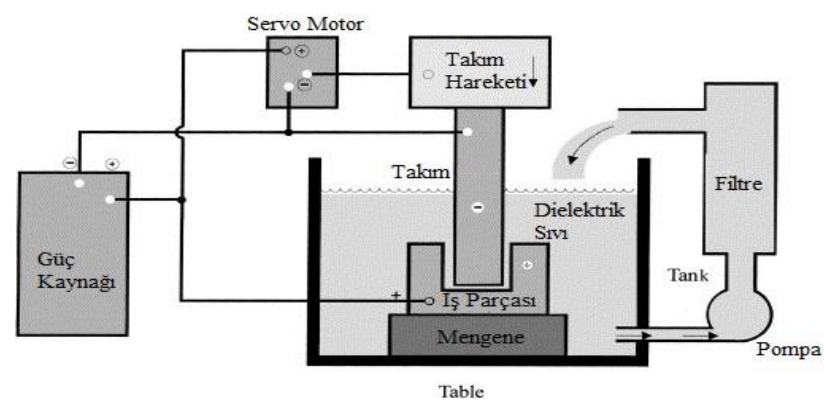

Şekil 1. EEİ şematik gösterimi 
Gerilim vurumlarının tekrarlı hareketi ile elektrot ile iş parçası arasında elektrik boşalımları oluşmaktadır. İş parçası ve elektrot arasında dielektrik sıvı bulunmaktadır. Elektrotlar ile iş parçası arasında işleme aralığı 0,01-0,5 mm'lik bir aralık kalması gerekmektedir. Boşalım akımı işleme aralıklarının büyüklügüne ve dielektrik ortam sıvısının yalıtkanlık direncine bağlı olmaktadır. Gerilim vurmunun uygulanmasının devamında elektrot ve iş parçası arasında bulunan en yakın iki yer arasında kanal iyonlaşır. Boşalım akımının temasta bulunduğu elektrot ve iş parçası yüzeyleri ergir ve buharlaşır. Sonuç olarak, iş parçasında ufak kraterler oluşacak şekilde parçacıklar kopar ve dielektrik sıvı yardımı ile işleme bölgesinden parçacıklar uzaklaştırılır. Mikro saniye düzeyinde gerçekleşen işlemeler boyunca iş parçası elektrotu üzerinde takım elektrot formunun negatifi oluşur.

Elektriksel iletkenliği bulunan her iş parçası sertlikleri dikkate alınmadan işlenebilmektedir. Geleneksel imalat yöntemleriyle işlenmeleri zor olan sertleştirilmiş karbür malzemelerin işlemesinde EEİ yöntemi kullanılmaktadır. EEİ sertleştirilmiş iş parçalarına kolaylıkla uygulanabilmektedir. Böylece sertleştirme işlemi sebebiyle meydana gelen deformasyon problemi çözülebilmektedir. İş parçası ve malzeme çifti arasında kesme kuvveti olmadığı için iş parçası içerisinde gerilmeler olmamaktadır. EEİ sonrasında ikincil bir operasyon ihtiyaç duyulmaması EEİ sağladığı avantajlardır. EEİ'de iş parçasından talaş kaldırma miktarının az olması ve işlenecek olan malzemenin iletken olması gerekliliği bu tekniğin sınırlandırmalarıdır.

Daha önce EEİ yapılan uygumalarda işleme sonrası iş parçası yüzey pürüzlülüğü, iş parçası işleme hızı ve elektrot aşınmasını inceleyen çalışmalar yapılmıştır. Her çalışmada amaç iş parçası ve elektrot çifti için uygun işleme parametrelerinin belirlenmesidir. Literatürde bulunan birçok çalışmada düşük işleme parametrelerinin kullanımının daha iyi yüzey pürüzlülüğü sağlayacağı belirtilmektedir. EEİ'de kullanılan parametrelerden özellikle boşalım akımı ve vurum sürelerinin yüzey pürüzlülüğü üzerinde etkili oldukları ifade edilmiştir (Torres vd., 2015:33; Chakraborty vd., 2015:1; Talla vd., 2015:369). EEİ tekniğinde önemli performans çıktıları İIHH ve EAH'dır. BA değeri EAH'nın İIH'na bölünmesiyle elde edilen bir diğer performs çıktısıdır. İmalat işlemenin kısa sürede tamamlanması için İ̈H'nın yüksek olması istenirken, EAH'nın düşük olması amaçlanmaktadır. İşleme süreci boyunca daha az aşınan elektrotlar daha iyi ölçüsel ve boyutsal doğruluk sağlamaktadır. Yüksek boşalım akımı kullanmak EEİ operasyonlarında İİH artırmaktadır. Fakat bu durum aynı zamanda EAH yükseltmektedir (Hourmand vd., 2015:831; Unune ve Mali, 2016:2082; Singh vd., 2016:456; Pei vd., 2017:31). Bu duruma paralel olarak 
BA değerleri de yükselmektedir. EEİ'de amaç yüksek IIIH hızlarında düşük EAH elde etmektedir. Bu durum ancak en uygun işleme parametreleri kullanılarak gerçekleştirilebilir.

EEİ'de iş parçasının arzu edilen kalitede üretilebilmesi ve işlem zamanın kısaltılabilmesi işleme parametrelerinin seçilimine bağlı olarak değişmektedir. Çok sayıdaki bu parametrelerin seçilmesi işlemeyi doğrudan etkilemektedir ve doğru bir şekilde belirlenmesi gerekmektedir. Bu amaçla bu çalışmada EEİ metodu ile AISI D2 soğuk iş takım çeliğinin bakır elektrot kullanılarak işlenebilirlik performans çıktıları olan yüzey pürüzlülügü, iş parçası işleme hızı, elektrot aşınma hızı ve bağılma aşınma için optimizasyon çalışması yapılmıştır. Verimli bir EEİ tekniğgi gerçekleştirmek için işleme parametreleri optimize edilmiştir. Deneysel sonuçlar oluşturulan grafikler yardımıyla yorumlanmıştır.

\section{MALZEME VE METOD}

Deneysel çalışma için FURKAN marka "EDM M25A" elektro erozyon tezgahı kullanılmıştır. EEİ deneylerinde iş parçası olarak AISI D2 soğuk iş takım çeliği kullanılmıştır. Kaba iş parçası freze tezgahında $61 \times 221 \times 26 \mathrm{~mm}$ ölçülerine işlenmiştir. Daha sonra taşlama tezgahında işlenerek parça 60x220x25 mm ölçüsüne taşlanmıştır. İş parçasına ait kimyasal kompozisyon Tablo 1'de gösterilmektedir.

Tablo 1. AISI D2 soğuk takım çeliğinin kimyasal kompozisyonu

\begin{tabular}{|c|c|c|c|c|c|c|c|c|}
\hline Element & $\mathrm{C}$ & $\mathrm{Mn}$ & $\mathrm{Cr}$ & $\mathrm{Mo}$ & $\mathrm{V}$ & $\mathrm{Si}$ & $\mathrm{P}$ & $\mathrm{Fe}$ \\
\hline \% A ğırlık & 1.55 & 0.4 & 11.8 & 0.8 & 0.8 & 0.3 & 0.018 & Diğer \\
\hline
\end{tabular}

Deneysel çalışmada ÖZ-KA Metal firmasından ticari olarak elde edilmiş CuETP R280 kodlu elektrolitik bakır kullanılmıştır. Elektrotlar 15x15 mm ölçülerinde olup freze tezgahında $100 \mathrm{~mm}$ boyunda olacak şekilde frezelenmiştir. Frezeleme operasyonun ardından her bir elektrot 180, 320, 600, 800 ve 1200 grid zımparalarla aşındırılmıştır. Elektrolitik bakıra ait fiziksel özellikler Tablo 2'de gösterilmektedir. Dieleketrik ortam sıvısı olarak kerosene kullanılmıştır. Dielektrik ortam sıvı yanal püskürtülmüş̧ür. Kutuplama elektrot için $(+)$, iş parçası için (-) olarak ayarlanmıştır. Her bir deney parametresi için 60 dakika işleme yapılmıştır. 
Tablo 2. Bakır elektroda ait fiziksel özellikler

\begin{tabular}{|c|c|}
\hline Çekme mukavemeti (MPa) & 290,28 \\
\hline Kopma uzaması (\%) & 14,31 \\
\hline Sertlik (HB) & 99,64 \\
\hline Saflık (\%) & 99,975 \\
\hline Elektrik iletkenliği (MS/m) & 57,61 \\
\hline Hacimsel özdirenç $\left(\Omega \mathrm{mm}^{3} / \mathrm{m}\right)$ & 0,01736 \\
\hline
\end{tabular}

Deneysel çalışmada işlenebilirlik üzerinde en etkili parametreler olan boşalım akımı ve vurum süresi için üç farklı parametre kullanılmıştır. Boşalım akımı için 6-12-25 A seviyeleri, vurum süresi için 50-100-200 $\mu$ sn seviyeleri belirlenmiştir. Bekleme süresi 200 $\mu$ sn sabit kullanılmıştır. İşlenebilirlik parametrlerinin yüzey pürüzlülüğüne, iş parçası işleme hızına, elektrot aşınma hızına ve bağıl aşınmaya, olan etkileri incelenmiştir. Eşitlik 1, 2 ve 3'teki denklemler kullanılarak iş parçası işleme hızı, elektrot aşınma hızı ve bağıl aşınma değerleri hesaplanmıştır. Ortalama yüzey pürüzlülük (Ra) ölçümü yapılabilmesi için işleme esnasında elektrot parçanın $3 \mathrm{~mm}$ dışında bırakılmıştır. Yüzey pürüzlülük ölçümleri Mitutoyo marka SJ 410 model cihaz ile ölçülmüştür. Yüzey pürüzlülük değeri ortalama yüzey pürüzlülüğü $(\mathrm{Ra})$ olarak ölçülmüştür. İşleme öncesi ve işleme sonrası elektrotların ağırlıkları hassas terazide tartılarak, işleme sonrası oluşan ağırlık kayıpları ölçülmüştür.

$$
\begin{aligned}
& \dot{\mathrm{I}} H\left(\mathrm{~mm}^{3} / \text { dak }\right)=\frac{\text { İş parçası toplam aşınma hacmi }\left(\mathrm{mm}^{3}\right)}{\text { Toplam işleme süresi }(\text { dak })} \\
& E A H\left(\mathrm{~mm}^{3} / \text { dak }\right)=\frac{\text { Elektrot toplam aşınma hacmi }\left(\mathrm{mm}^{3}\right)}{\text { Toplam işleme süresi }(\text { dak })} \\
& B A(\%)=\frac{E A H}{\mathrm{I} \dot{\mathrm{I} H}} X 100
\end{aligned}
$$

\section{DENEYSEL SONUÇLAR VE TARTIŞMA}

Deneysel çalışma sonrasında ölçülen yüzey pürüzlülüğü sonuçları ve eşitlik 1,2 ve 3 kullanılarak hesaplanan IIIH, EAH ve BA değerleri Tablo 3'te gösterilmektedir. Tablo 3'te yüzey pürüzlülüğünün, IIIH ve EAH artan boşalım akımı ve vurum süreleri ile beraber arttığ1 görülmektedir. Düşük boşalım akımı ve vurum süreleri daha iyi bir yüzey pürüzlülügüü, düşük işleme hızı ve düşük elektrot aşınma hızları oluşturduğu görülmektedir. Bağıl aşınma elektrot aşınma hızına ve iş parçası işleme hızına bağlı olarak değiştiği görülmektedir. 
Kalyon, $A$.

Tablo 3. Deneysel sonuçlar

\begin{tabular}{|c|c|c|c|c|c|c|}
\hline Sira & $\begin{array}{c}\text { Güç } \\
\text { Seviyesi }(\mathrm{A})\end{array}$ & $\begin{array}{c}\text { Ark Süresi } \\
(\mu \mathrm{sn})\end{array}$ & $\begin{array}{c}\mathrm{Ra} \\
(\mu \mathrm{m})\end{array}$ & $\begin{array}{c}\text { İIH } \\
\left(\mathrm{mm}^{3} / \mathrm{dak}\right)\end{array}$ & $\begin{array}{c}\text { EAH } \\
\left(\mathrm{mm}^{3} / \mathrm{dak}\right)\end{array}$ & BA $(\%)$ \\
\hline 1 & 6 & 50 & 4,15 & 0,9 & 0,0019 & 0,2143 \\
\hline 2 & 6 & 100 & 4,69 & 1,2 & 0,0027 & 0,2225 \\
\hline 3 & 6 & 200 & 5,41 & 1,5 & 0,0341 & 2,2744 \\
\hline 4 & 12 & 50 & 6,48 & 2,4 & 0,0564 & 2,3486 \\
\hline 5 & 12 & 100 & 8,75 & 3,6 & 0,0668 & 1,8542 \\
\hline 6 & 12 & 200 & 9,21 & 4,8 & 0,0860 & 1,7924 \\
\hline 7 & 25 & 50 & 9,41 & 6 & 0,1387 & 2,3115 \\
\hline 8 & 25 & 100 & 10,33 & 8,7 & 0,1469 & 1,6879 \\
\hline 9 & 25 & 200 & 13,77 & 12,9 & 0,1780 & 1,3798 \\
\hline
\end{tabular}

\subsection{Yüzey Pürüzlülüğünün Değerlendirilmesi}

Farklı boşalım akımı ve vurum süresi koşullarında ölçülen yüzeylerin Ra değerlerine ait grafik Şekil 2'de gösterilmektedir. En düşük Ra değeri $4.15 \mu$ m olarak boşalım akımın 6 A ve vurum süresinin $50 \mu$ sn olduğu işleme şartlarında elde edilmiştir. En yüksek yüzey pürüzlülüğü boşalım akının 25 A ve vurum süresinin $200 \mu$ sn olduğu deney şartlarında 13.77 $\mu \mathrm{m}$ ölçülmüştür. Şekil 2 incelendiğinde artan boşalım akımı ile birlikte yüzey pürüzlülüğün $\operatorname{arttığ1~görülmektedir.~Aynı~şekil~vurum~süresindeki~artışlarda~yüzey~pürüzlülüğünü~olumsuz~}$ etkilemektedir.

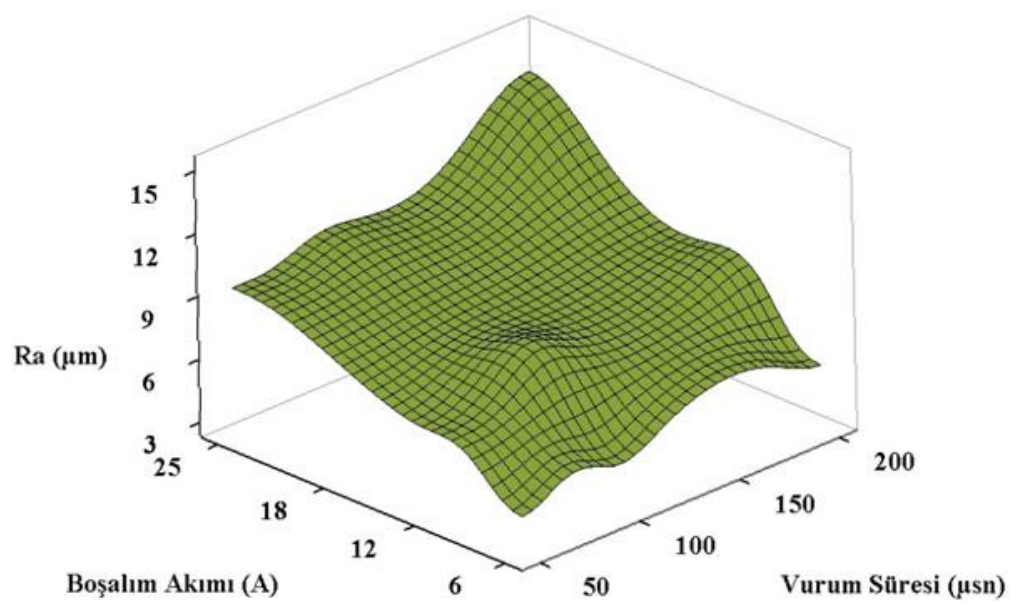

Şekil 2. Boşalım akımı ve ark süresinin yüzey pürüzlülüğüne etkileri

Ra değerleri boşalım akımı ve vurum süresindeki artışlardan olumsuz etkilendiği görülmektedir. Boşalım akımının artması iş parçasından ergiyen ve buharlaşan parçacık miktarını arttırmaktadır. Bu durum iş parçası yüzeyinde daha büyük kraterlerin oluşmasına neden olmaktadır. Krater büyüklüğünün artması Ra değerinin artmasına sebep olmaktadır 
(Yılmaz vd. 2015:417). Şekil 3'te sırasıyla $200 \mu$ sn vurum süresinde 6A, 12A, 25 A boşalım akımlarında elde edilen yüzeylere ait SEM görüntüleri verilmektedir. Yüzeylerde malzemeden kaldırılan ve sıvı basıncı ile ara bölge kalan küresel partiküller, eriyerek yüzeye damla şeklinde yapışan döküntüler, çatlak, kalıntı ve farklı boyutlarda oluşmuş kraterler görülmektedir. Bu kraterler, işleme sırasında her bir kıvılcımın etkisi ile yüzeyden kaldırılan küresel talaşların meydana getirdiği oyuklardır. EEİ, her bir elektriksel boşalım sonucunda oldukça yüksek ısı meydana gelir ve bu oluşan ısının etkisi ile iş parçasının yüzeyi yerel olarak ergir ve buharlaşır. Bu sebeple EİI'de işlenmiş yüzeyler yönsüz bir profile sahip olmaktadır (Nguyen vd., 2018: 109). Şekil incelendiğinde boşalım akımının artması yüzeyde oluşan kraterlerin daha geniş olduğu görülmektedir. Bu durum yüzeyin daha fazla kaba bir yapıya sahip olmasına neden olmaktadır.

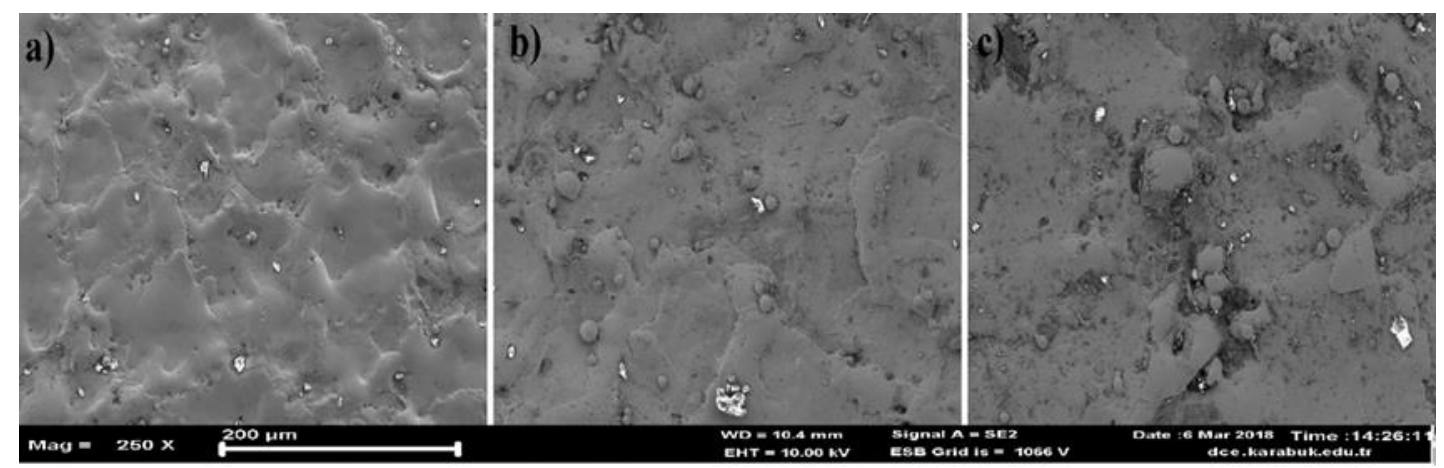

Şekil 3. İşlenmiş yüzeylere ait SEM görüntüleri a) 6 A b)12 A c)25 A

Şekil 4'te $200 \mu$ sn vurum süresin ve 25 A boşalım akımda yüzeyden elde edilen görüntüde yüksek akımın yüzeyde meydana getirmiş olduğu çatlaklar rahatlikla gözlemlenebilmektedir. Mevcut bu çatlaklar işleme sonrası kaba bir yüzeyin oluşmasına neden olmaktadır.

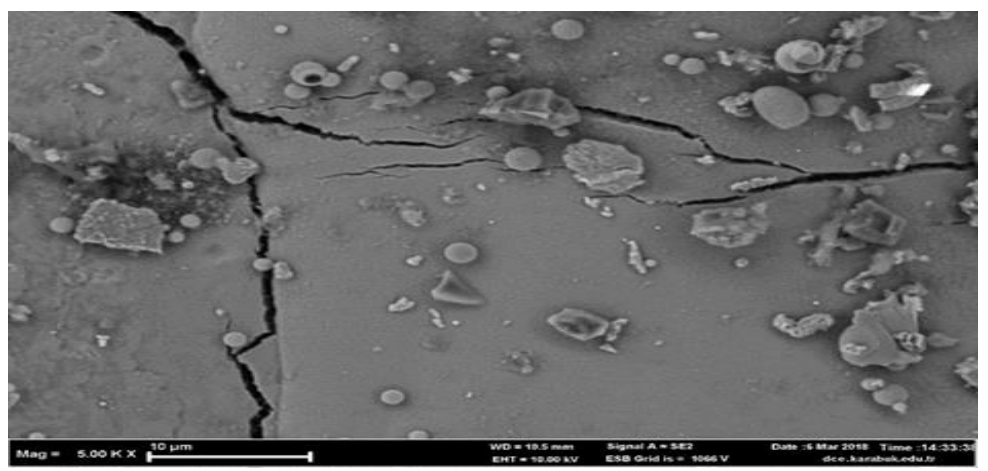

Şekil 4. 25 A boşalım akımı ve $200 \mu$ sn vurum süresinde elde edilen yüzeyin detaylı görüntüsü 
Vurum süresi elektrottan iş parçasına gerçekleşen boşalım akım aralığıdır. Vurum süresinin artması iş parçasının yüzeyine daha fazla 1sı enerjisinin transfer edilmesine neden olmaktadır. Bu durum artan vurum sürelerinde yüzey pürüzlülüğünün olumsuz etkilenmesine neden olmaktadır (Kumar 2015: 105; Hourmand vd., 2015:831). Şekil 2'de artan vurum süreleriyle beraber yüzey pürüzlülüğünün arttığı görülmektedir.

\section{2. İIH Değerlendirilmesi}

İ̈H birim sürede, malzemeden kaldırılan talaş miktarı olarak ifade edilmektedir. EEİ çalışmalarında İIHH yüksek olması amaçlanmaktadır. Boşalım akımı ve vurum süresinin İİH etkisi Şekil 5'te gösterilmektedir. Şekil 5 değerlendirildiğinde boşalım akımı ile İ̈H arasında doğru orantı olduğu görülmektedir. Boşalım akımın artması iş parçası işleme hızını arttırmaktadır. Vurum süresinin artmasıyla İ̈H aynı şekilde artmaktadır. Şekil 5'de bulunan grafik incelendiğinde boşalım akımın İ̈H etkisinin vurum süresinden daha fazla olduğu anlaşılmaktadır. En yüksek İİH $12.9 \mathrm{~mm} 3 /$ dak olarak, boşalım akımının $25 \mathrm{~A}$ ve vurum süresinin $200 \mu$ sn olduğu deney şartında, en düşük İ̈H 0.9 mm3/dak boşalım akımının 6 A, vurum süresinin $50 \mu$ sn olduğu deney şartında elde edilmiştir.

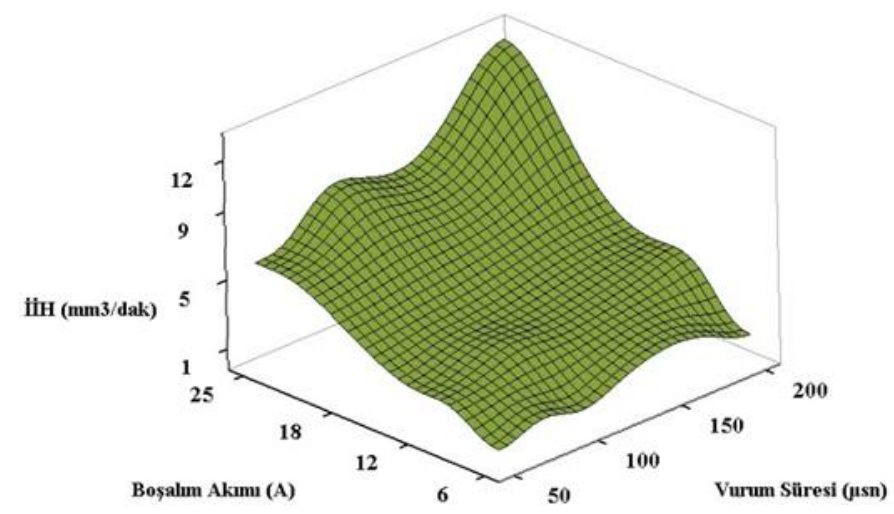

Şekil 5. Boşalım akımı ve vurum süresinin İïH etkisi

İş parçası yüzeyinde elektriksek boşalımlar ile meydana gelen krater boyutlarının boşalım akımı ile beraber artması EEİ tekniğinin çalışma prensibidir. Bunun sebebi, boşalım akımının artması, boşalım enerjisi ile iş parçası yüzeyinden daha fazla malzemenin ergitilip buharlaştırılmasıdır. Böylece, boşalım akımının artması ile birlikte her bir kıvılcımın şiddeti de artmaktadır. Şiddeti artan kıvılcımlar iş parçası üzerinden daha büyük hacmi kaldırmaktadır. $\mathrm{Bu}$ durum daha kısa sürede daha fazla hacim ergitilip buharlaştırmaktadır (Y1lmaz vd., 2015: 417). Şekil 6'da 25 A ve $200 \mu$ sn de işlenmiş yüzeyin SEM görüntüsü verilmektedir. Şekil incelendiğinde yüzeyde oluşan kraterler rahatlıkla görülmektedir. Aynı 
zamanda yüzeyden kopan parçacıkların dielektrik sıvının etkisi ile soğuyarak yüzeye yapışan partiküller olduğu görülmektedir.

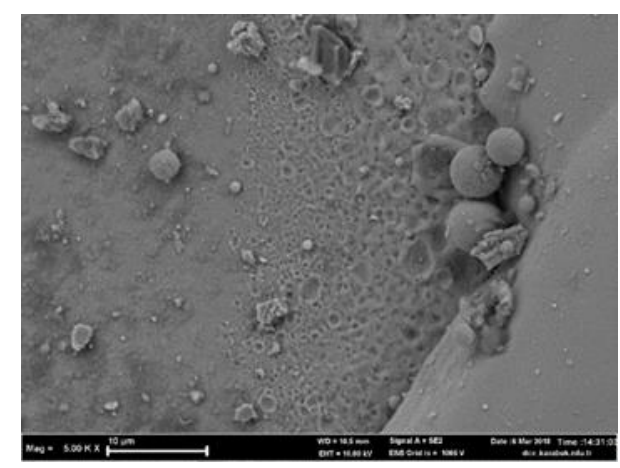

Şekil 6. 25 A boşalım akımı ve $200 \mu$ sn vurum süresinde işlenmiş yüzeyin SEM görüntüsü

\subsection{EAH Değerlendirilmesi}

EEİ işlemlerinde iş parçası ve elektrot çifti arasında oluşan kıvılcımlar sadece iş parçasından değil aynı şekilde elektrotta belirli bir hacmi eritir ve buharlaşmasına sebep olur. EEİ'de elektrottan beklenen özellikler iyi bir elektrik iletkenliği ve aşınmaya karşı dirençli olmasıdır (Hadad vd., 2018:2093) Elektrotta gerçekleşen aşınma, elektrot malzeme cinsine, kullanılan boşalım akımı enerjisi seviyesine bağlıdır. Genel olarak elektrot erime sıcaklığı ne kadar yüksek ise aşınma oranı o kadar düşük olmaktadır. Şekil 7'de işleme parametrelerine bağlı olarak elde edilen aşınma değerleri yüzey grafiğinde gösterilmektedir.

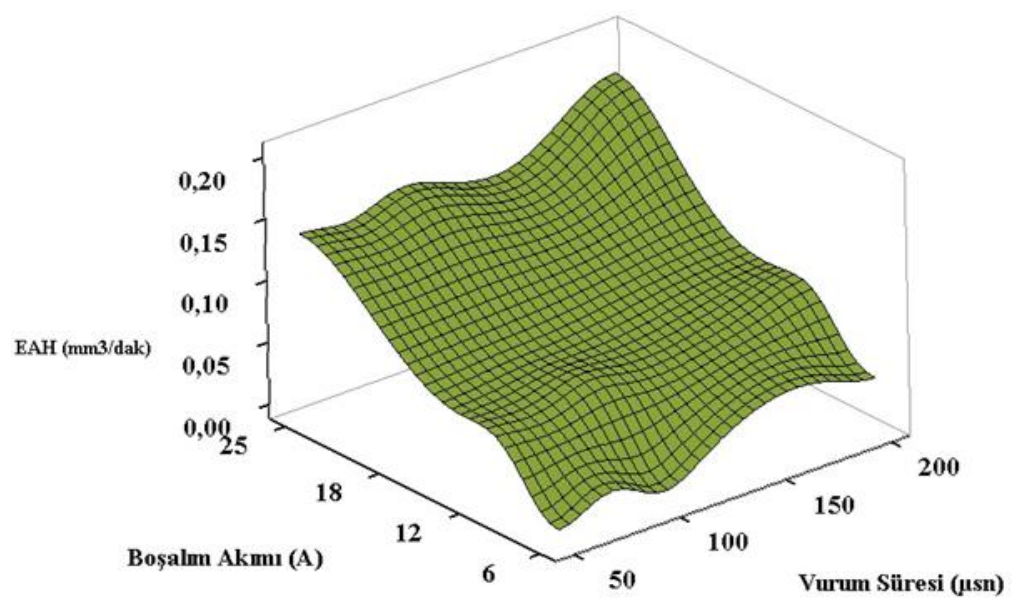

Şekil 7. Boşalım akımı ve ark süresinin elektrot aşınmasına etkisi

Grafik incelendiğinde güç seviyesinin artışına bağlı olarak elektrotta daha fazla aşınma meydana geldi görülmektedir. En düşük elektrot aşınma miktarı boşalım akımının en düşük kullanıldığı parametre değeri olan 6 A ve vurum süresinin $50 \mu$ sn 0,0019 olarak 
belirlenmiştir. 25 A boşalım akımı ve $200 \mu \mathrm{sn}$ vurum süresinde $0,178 \mathrm{~mm} 3 /$ dak elektrotta aşınma olduğu ölçülmüştür. Yine aynı şekilde boşalım akımının artışına benzer şekilde vurum süresindeki artışlar elektrotun daha fazla aşınmasına neden olmaktadır. Şekil 8'de $200 \mu$ sn vurum süresinde, boşalım akımının 12 A ve 25 A olduğu seviyelerde elektrotların yan yüzeylerinin optik mikroskop görüntüleri verilmektedir. Boşalım akımının artması boşalım esnasında plazma kanalındaki genişlemenin etkisiyle elektrot yüzeylerinde bir karbon tabakasının birikmesine neden olmaktadır. $\mathrm{Bu}$ durum elektrot boşalım yüzeyinin kaplanmasına ve etkin bir boşalımın gerçekleşmesinin engelleyen bir durum olarak ortaya çıkmaktadır.
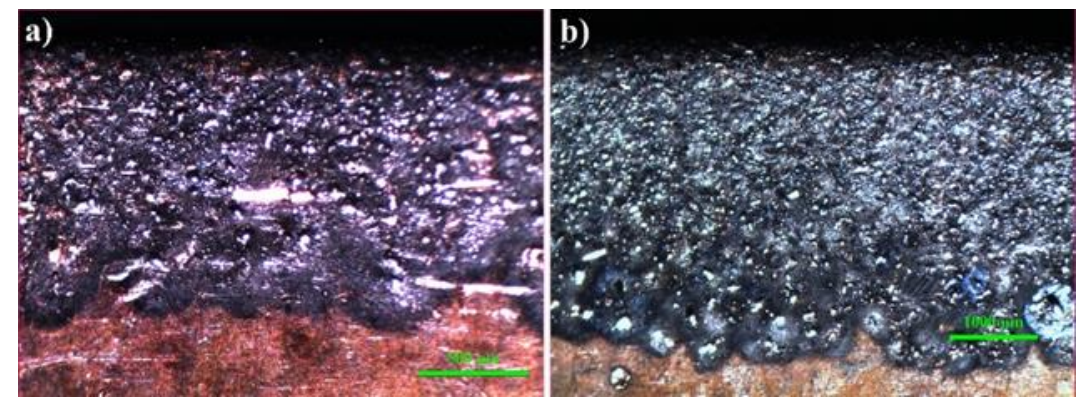

Şekil 8. Elektrot yüzeylerinde oluşan karbon tabakası a) 12 A b) 25 A

\subsection{BA Değerlendirilmesi}

Bağıl aşınma, EEI'de işlem süresince EAH ve İIH arasındaki bağıntıyı açıklayan bir çıktıdır. Deneyler sonucunda elde edilen veriler kullanılarak hesaplana BA değerlerine ait boşalım akımı ve vurum süresi etki grafiği Şekil 9'da gösterilmektedir. Şekil 9'da bağıl aşınmanın düşük boşalım akımları ve düşük vurum sürelerinde düşük seviyelerde olduğu görülmektedir. $\mathrm{Bu}$ durum düşük işleme parametrelerinde elektrot aşınmasının nispeten düşük olması, bunun yanında İ̈H hızının yüksek olmasından kaynaklanmaktadır. Yüksek boşalım akımı ve yüksek vurum seviyelerinde elekrotta meydana aşındırmayı hızlandırması, aşınan elektrotun İ̈HH hızının düşmesi belirli seviyeden sonra BA değerinin artmasına neden olduğu görülmektedir (Torres vd., 2015:33). Çizelge 3 incelendiğinde en düşük bağıl aşınma \%0,21 olarak 6 A boşalım akımı ve $50 \mu$ sn vurum süresi kullanıldığı işleme parametrelerinde elde edilmiştir. Boşalım akımı arttıkça artan elektrot aşınması ve düşük vurum süresinde elde edilen İ̈H, deneysel çalışmada en yüksek bağıl aşınmanın 12 A, $50 \mu$ sn parametrelerin kullanıldığ deneyde \%2,34 olarak elde edilmiştir. 


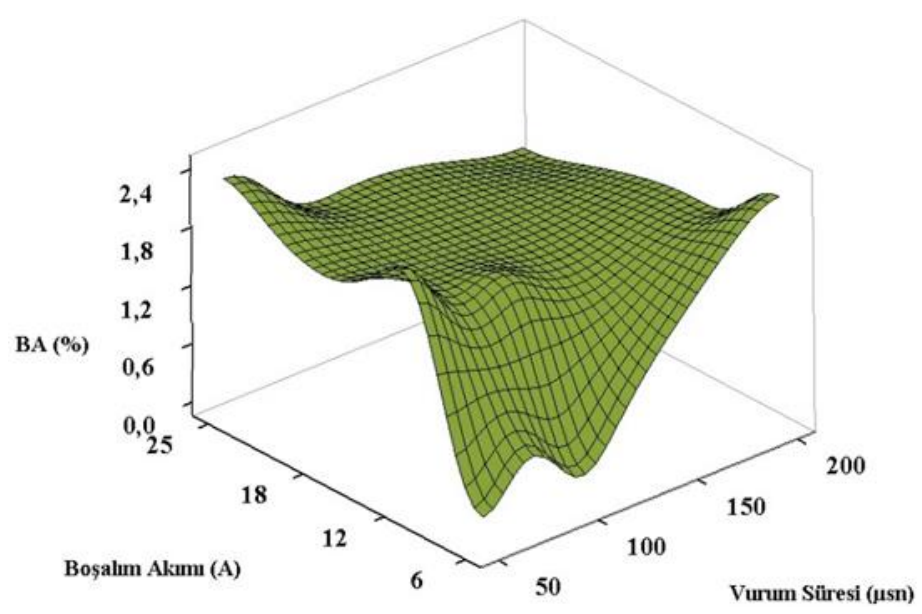

Şekil 9. Boşalım akımı ve ark süresinin bağıl aşınmaya etkisi

\section{SONUÇLAR}

$\mathrm{Bu}$ çalışmada EEİ tekniği kullanılarak işleme parametrelerinin iş parçası yüzey pürüzlülüğü, İIH, EAH ve BA üzerine etkileri deneysel olarak incelenmiştir. Deneysel çalışma sonucunda boşalım akımının artması iş parçası yüzey pürüzlülüğünü, İ̈H, EAH arttırdığı belirlenmiştir. Aynı şekilde vurum sürelerinin artması yüzey pürüzlülügü ve EAH hızını olumsuz etkilediği görülmüştür. İİH hızının vurum süresinin artmasıyla arttığı belirlenmiştir. Deneysel çalışma sonunda elde edilen grafikler işlem çıktılarının en fazla boşalım akımı değerlerinden etkilendiğini göstermektedir. Bağıl aşınma elektrotta meydana gelen aşınma değerlerinin yüksek boşalım değerlerinde artmasından ve elektrotun işleme kabiliyetinin azalmasından dolayı, yüksek işleme seviyelerinin bağıl aşınmanın artmasına neden olduğu görülmüştür. Yüksek boşalım akımı değerlerinin EEİ kaba işlemler için uygun olduğu görülmüştür. Son nihai yüzey ve ölçüleri elde etmek için düşük boşalım akımı ve kısa vurum sürelerinin kullanılmasının uygun olduğu belirlenmiştir.

\section{REFERENCES / KAYNAKLAR}

Anjum, S., Shah, M., Anjum, N. A., Mehmood, S. \& Anwar, W. (2017). Machining and surface characteristics of AISI 304L after electric discharge machining for copper and graphite electrodes in different dielectric liquids. Engineering, Technology \& Applied Science Research, 7(4), 1765-1770.

Chakraborty, S., Dey, V. \& Ghosh, S. K. (2015). A review on the use of dielectric fluids and their effects in electrical discharge machining characteristics. Precision Engineering, 40, 1-6.

Hadad, M., Bui, L. Q. \& Nguyen, C. T. (2018). Experimental investigation of the effects of tool initial surface roughness on the electrical discharge machining (EDM) performance. The International Journal of Advanced Manufacturing Technology, 95(5-8), 2093-2104. 
Hourmand, M., Farahany, S., Sarhan, A. A. \& Noordin, M. Y. (2015). Investigating the electrical discharge machining (EDM) parameter effects on Al-Mg 2 Si metal matrix composite (MMC) for high material removal rate (MRR) and less EWR-RSM approach. The International Journal of Advanced Manufacturing Technology, 77(5-8), 831-838.

Jamwal, A., Aggarwal, A., Gautam, N. \& Devarapalli, A. (2018). Electro-discharge machining: recent developments and trends. International Research Journal of Engineering and Technology, 5(2), 433-448

Kumar, H. (2015). Development of mirror like surface characteristics using nano powder mixed electric discharge machining (NPMEDM). The International Journal of Advanced Manufacturing Technology, 76(1-4), $105-113$

Kumar, S., Batish, A., Singh, R. \& Bhattacharya, A. (2017). Effect of cryogenically treated copper-tungsten electrode on tool wear rate during electro-discharge machining of Ti-5Al-2.5 Sn alloy. Wear, 386, 223-229.

Kumari, S., Datta, S., Masanta, M., Nandi, G. \& Pal, P. K. (2018). Electro-discharge machining of Inconel 825 Super alloy: effects of tool material and dielectric flushing. Silicon, 10(5), 2079-2099.

Nguyen, P., Banh, L., Bui, V. \& Hoang, D. (2018). Multi-response optimization of process parameters for powder mixed electro-discharge machining according to the surface roughness and surface micro-hardness using Taguchi-TOPSIS. International Journal of Data and Network Science, 2(4), 109-119.

Pei, J., Zhang, L., Du, J., Zhuang, X., Zhou, Z., Wu, S. \& Zhu, Y. (2017). A model of tool wear in electrical discharge machining process based on electromagnetic theory. International Journal of Machine Tools and Manufacture, 117, 31-41.

Singh, B., Kumar, J. \& Kumar, S. (2016). Investigation of the tool wear rate in tungsten powder-mixed electric discharge machining of AA6061/10\% SiCp composite. Materials and Manufacturing Processes, 31(4), 456-466.

Talla, G., Sahoo, D. K., Gangopadhyay, S. \& Biswas, C. K. (2015). Modeling and multi-objective optimization of powder mixed electric discharge machining process of aluminum/alumina metal matrix composite. Engineering Science and Technology, an International Journal, 18(3), 369-373.

Torres, A., Puertas, I. \& Luis, C. J. (2015). Modelling of surface finish, electrode wear and material removal rate in electrical discharge machining of hard-to-machine alloys. Precision Engineering, 40, 33-45.

Unune, D. R. \& Mali, H. S. (2016). Artificial neural network-based and response surface methodology-based predictive models for material removal rate and surface roughness during electro-discharge diamond grinding of Inconel 718. Proceedings of the Institution of Mechanical Engineers, Part B: Journal of Engineering Manufacture, 230(11), 2082-2091.

Yılmaz, V., Özdemir, M. \& Dilipak, H. (2015). AISI 1040 çeliğinin elektro erozyon ile işleme yöntemiyle delinmesinde işleme parametrelerinin temel performans çıktıları üzerindeki etkilerinin incelenmesi. Gazi Üniversitesi Fen Bilimleri Dergisi Part:C, 3(1), 417-426. 